\title{
Exploring the Impact of Ineffective Formal Communication between Teachers and Students: A Case Study of Mustaqbal University and Jubail University College, Kingdom of Saudi Arabia
}

\author{
Hanan Albalawi ${ }^{1}$ \& Muhammad Nadeem ${ }^{2}$ \\ ${ }^{1}$ English Language Department, Jubail University College, Jubail, KSA \\ ${ }^{2}$ English Language Department, Administration and Humanities College, Mustaqbal University, Buraidah, KSA \\ Correspondence: Hanan Albalawi, English Language Department, Jubail University College, Jubail, KSA
}

Received: January 1, 2020

Accepted: February 16, $2020 \quad$ Online Published: February 19, 2020

doi: $10.5539 /$ elt.v13n3p68

URL: https://doi.org/10.5539/elt.v13n3p68

\begin{abstract}
This study investigates the specific barriers to effective communication by teachers and students of the EFL programs of higher education in the Saudi Kingdom. The study utilized a qualitative design to examine perspectives of EFL students and the faculty members of the EFL programs at Al-Mustaqbal and Jubail University College on the effects, causes and viable solutions to ineffective communication between teachers and students. Data collection involved interactive methods which included using open-ended questionnaires and online focus groups respectively. Overall, 39\% agreed that poor and ineffective communication is common between teachers and students, and $44 \%$ agreed that it was a cause of poor performances for students in EFL programs; while $17 \%$ indicated that ineffective communication between teachers and students was to blame for the poor quality of engagement of students with their teachers. The findings qualify the critical significance of considering the implementation of motivating methodologies for improving teacher-student communication.
\end{abstract}

Keywords: preparatory program, EFL, Saudi students, learning factors, effective communication, teaching English

\section{Introduction}

Defined as the process of transmitting, receiving and decoding of ideas, communication is a vital enabler of effective and productive human interactions and engagements. According to Saunders and Mills (1999), there are four main skills involved in communication engagements by individuals, listening, speaking, reading and writing, and that the effectiveness of the process of communication is heavily dependent on the extent of shared understanding of the contexts in which the communication takes place. For Criper and Widdowson (1975), the act of sending or transmitting and receiving a message qualifies communication as a physical operation involving an addresser as the source of a communication message directing their message to an addressee or the target recipient of the message. The implication here is that communication is both an act as such relates to the generating of a message and a process. In particular, it is a process because it is all about ensuring the intended message is successfully transmitted to the intended recipient and interpreted as intended.

On the contrary, according to Neill (2017), communication in the context of teaching and learning differs from normal communication in a variety of ways. In particular, unlike in normal communication engagements, the communication between teachers and students is grounded on the existence of a formal relationship bond. As such, it involves upholding the norms and values of the field of teaching while communicating. In a language classroom, more than often, the teacher acts as an addresser or a speaker, whereas, a student acts as an addressee or a listener. Besides, teacher communication skills are important for a teacher in the delivery of education to students (Burns \& Seidlhofer, 2010). However, as in normal communication, communication between teachers and students entails the decoding of the ideas by the students as transmitted by the teacher. Furthermore, communication between teachers and students is also influenced by the guide-learner relationship.

\subsection{Research Problem}

In practice, however, although the formality of the communication between teachers and students is meant for enhancing the success prospects of the teaching-learning process, there are numerous incidents in which the 
process fails to achieve desired results (Khan, 2011). Effective communication between teachers and students is meant for creating a positive classroom environment, an element that is usually inhibited by the failure of teachers to engage their students. The result of such is a situation in which students are forced to unduly struggle to maintain focus on the subject matter (Khan, et al., 2018a). Numerous studies have indicated on the critical role that modern technology has as a critical determinant of the nature of communication in the modern classroom (Khan et al., 2019; Khan, et al., 2018a; Khan, et al., 2018b; Shahbaz, et al., 2016; Shahbaz \& Khan, 2017). To this end, there are a variety of issues to blame for ineffective communication between teachers and students.

Of particular significance, with most of the English teachers in these programs being non-natives, the teaching process generally involves the direct method of teaching. Unfortunately, the outcome of such programs continues to be characterized by low achievement or unsatisfactory and far below the expectations in EFL among students despite numerous policy attempts by the Saudi government to improve on the teaching and learning of English in the country (Shahbaz \& Khan, 2017; Khan et al., 2019; Khan, et al., 2018a). According to Shahbaz and Khan (2017), the problem can be blamed on a variety of factors such as unknown expectations, problems with comprehension, boring classroom lessons, personality differences, cultural difference, negative attitude from both parties, peer pressure and the lack of effective training of teachers to ensure their context-specific proficiency. Notably, these factors lead to compromising the effectiveness of formal communication between teachers and students.

According to Fageeh (2013), failure by EFL institutes in Saudi Arabia to achieve desired goals has caused serious concerns among different stakeholders to the education systems in the Kingdom. Though there is evidence of numerous questions surrounding this failure, teachers are in record for complaining of the inability of students to comprehend the lessons (Fageeh, 2013). As noted by Alhmadi (2014), "despite the attempts of the Saudi government to effectively plan a comprehensive curriculum and to provide textbooks, the teaching-learning process seems futile because actual skills' development is lacking" (p.40).

Mustaqbal University and Jubail University college in Saudi Arabia offer post-secondary education EFL programs to students interested in furthering their education in English. However, like other EFL students and teachers in Saudi Arabia, these programs suffer an inherent challenge in achieving effective communication between students and teachers. The process of communication does not meet the required standards, an element which translates to the unsatisfactory performance of the students and the programs as a whole. Consequently, the purpose of this research study is to investigate the specific barriers to effective communication by teachers and students of the EFL programs in these two major institutions of higher learning in the Saudi Kingdom. In particular, based on the findings from this study, the researcher seeks to determine and recommend feasible evidence-based solutions to the barriers to effective formal communication between students and faculty members.

\subsection{Research Questions}

To achieve its aims and objectives, this study specifically delves to answers the following three major research questions:

1. What forms of communication strategies are currently in common use between the faculty and EFL students in the EFL programs at the Mustaqbal University and Jubail University college?

2. What are the effects of current formal communication approaches on the acquisition of linguistic skills by EFL students?

3. What are the main causes of ineffective formal communication between teachers and students and how to overcome such barriers?

\subsection{Significance of the Study}

The rationale behind this study is well-informed by the fact that failure by EFL institutes in Saudi Arabia to achieve desired goals has caused serious concerns among various stakeholders to the education systems in the Kingdom (Fageeh, 2013). As a viable solution to these concerns, the findings of this research will be of great value as a reliable source of empirical evidence and insights to revealing the actual causes and risk factors to ineffective formal communication as the main reason for persistent problem of unsatisfactory performance of EFL programs at the two institutions and in other institutes across the Kingdom. More notably, the current study also seeks to explore feasible solutions and/or strategies for addressing the issue of ineffective communication. As a result, the findings of this study will be a great contribution to the existing literature not just on the causes of ineffective communication between teachers and EFL students and associated impact of EFL program outcomes, but more notably on evidence-based strategies for enhancing effective communication. Furthermore, by serving as informed research aimed at tackling the problem, the outcome of the study promises great value for use in improving the 
communication between EFL students and teachers, and subsequently, leading to greater benefit in terms of the professional development of EFL students.

\section{Literature Review}

Velentzas and Broni (2014), the general definition of communication as the process of exchanging ideas among creatures is centered on the perspective of the process of exchanging the ideas or messages as one that must be aimed at and guided to result into the realization of a common understanding amongst the parties involved. This is clear given the criticality of communication to success in all aspects of human life. According to Lunenburg (2010), on the other hand, there is great value in investing in research studies on communication owing to the understanding that every administrative function and related activities is founded on some form of communication, direct or indirect. As an emphasis, from planning and organizing to leading and monitoring day-to-day operations in an organization, managers or leaders must engage in communicating with and through other people to get things done.

Human beings are blessed with the attribute of communicating with others in different ways. To this end, they not only are engaged in using different ways of communicating with each other but more importantly, communication holds a critical position to engagements of humans in teaching and learning new knowledge and skills (Alrashidi \& Phan, 2015). For Alrashidi and Phan (2015), the success prospects of the teaching and learning interaction inside a classroom heavily depend on the successful transmitting or exchanging of ideas and information between the teachers and his/her students. Here, to ensure competitiveness in the exchanging ideas and information between teachers and students, it is imperative to ensure a congenial classroom atmosphere. According to Alrabai (2016), effective communication entails more than the mere exchanging of ideas - it involves relating to the ideas being exchanged with the emotions behind the ideas and information.

For Alrabai (2016), ineffective communication between teachers and students presents in a variety of ways such as through disruption in the due course of communication. According to this study, disruptions during communication are a common occurrence in the EFL teaching and learning process, and a leading cause for failures in effective conveying of the ideas being taught (Alrabai, 2016). Closely associated with this form of ineffective communication is the situation in which a person cannot understand written or communicated messages. Shahbaz and Khan (2017), however, note that the syllabus is the main hindrance to effective communication. Despite claims that it is carefully designed, it contains notable weak areas that need to be corrected. For example, according to Shahbaz and Khan (2017), the current syllabus does not give any emphasis on oral skills, an element that inhibits effective communication in the classroom. Furthermore, issues of unsystematic structural grading create problems for students to make sense of the structures (Shahbaz \& Khan, 2017).

There are also concerns over the inherent lack of learner-sensitive texts and vocabulary as it relates to engaging learners with content that best reflects their current EFL learning skills. The effect of such is the undue inhibition of the process of nurturing of self-efficacy and supporting a progressive learning experience among students (Dewaele \& Alfawzan, 2018). As noted by Al-Sobhi and Preece (2018), with this mismatch between content and the learning level of learners, most of the students try to avoid reading and writing of such texts and subsequent loss of interest using English for a communicative purpose. According to Al-Ahaydib (2005), even with efficacy in using English for communicative purposes, many EFL learners in the Kingdom poorly engage in communicating in English outside the classroom. This implicates on the prospects of retaining of content taught in the classroom through continued practicing in their daily lives (Alnujaidi, 2019). Still on quality of the syllabus, Ali and Rehman (2013) note of the problem of continued use of defective textbooks and books which were not written with careful consideration of their content in some of the states.

Moreover, Ali and Rehman (2013) have it that the issue of overcrowding of the typical EFL classroom translates the teaching-learning process into a mere lecturing engagement in which the students are forced to be passive listeners. Other issues of concern to the effectiveness of EFL teaching in Saudi Arabia include failure by the current education systems to invest in the proper training of local EFL teachers. According to Khan (2011), there is evidence of an inherent lack of concern by teachers on the need to clarify to students the aims and objectives of the English learning program and related units. This is complemented by the argument that some institutions are even promoting the use of grammar-translation method as a method for teaching English as a foreign language to students despite evidence that emphasis on grammar does not development all four basic skills of Language, and availability of more effective techniques such as structural and situational approaches (Mutambik, 2018). Such an approach promises a notable positive effect only on passing the examination.

According to Kiraly (2014), the problem of poor outcomes in the teaching and learning of EFL in the Saudi Kingdom can be blamed on the fact that "the mother tongue is so deeply embedded in our mental lives \& inner 
consciousness that learning the second language requires at first a different reaction to language one that is reorientation and in part a reorganization of consciousness" (P98). In terms of solutions, Khan et al. (2019) argue that the issue of ineffective communication can be reduced by the use of technology-based tools such as WhatsApp as means for fostering effective and frequent practicing with communicating in English by EFL learners. Other possible ways to reduce the intensity of ineffective communication is engaging learners with group conversations, as reliable platforms for enabling students to convey their messages easily and learning in the process (Lunenburg, 2010). This indicates the critical value of ensuring a relationship that supports, stimulates and encourages effective communication between teacher and students as a crucial determinant of successful learning outcomes for EFL learners. Here, teachers should both commit to inform and inspire students to be more confident, which will automatically lead to effective communication.

\section{Method}

\subsection{Research Design}

To achieve the research aims and objectives of this study, a qualitative design was utilized. In particular, this choice of the qualitative research design here was informed by the fact that compared to quantitative research design, a qualitative design is hailed for offering detailed, in-depth descriptions of the opinions, ideas, and experiences, while accounting for the influence of contextual factors (Rahman, 2016). Besides, according to Deville-Chalhoub and Deville (2008), there is a general preference for using qualitative approaches in research studies in which an emphasis is given to the search for more profound insights into issues related to administering, interpreting language, and assessing the quality of the communication. Accordingly, a qualitative study approach is well-informed for the current study.

\subsection{Study Population and Participants}

The target population of this study comprised EFL students and faculty members from Jubail University College and Mustaqbal University. It is apparent that students from both institutions have been associated with the presence of communication barriers, especially when interacting with their teachers. This is evidenced by the presence of relatively poor EFL performance among the students over the past several years. This made it necessary to look into the development of a sample space that comprises of both the students and teachers so that a clear picture of the underlying factors that have influenced the poor communication outcomes can be identified. A critical perspective of the self-reported issues by the students and the teachers would provide sufficient data to reveal the issues.

The sample space in the study comprised 84 students and 10 faculty members from the two institutions ( 43 female and 41 male). This population would facilitate accurate data regarding the gaps influencing poor communication.

\subsection{Data Collection}

To enhance the richness of the study data, data collection involved both interactive and participatory methods. It included using open-ended questionnaires and online focus groups. The use of open open-ended questionnaires was informed by the great benefits that such promises for enabling the collection of data involving diverse responses from the participants, and hence reducing the overall risk of bias that may arise from investigators in close-ended questionnaires (Reading Craze, 2017). On the other hand, as noted by Lotich (2011), focus group discussions provide a reliable platform in which discussions can be held and participants can air their ideas and suggestions with the end effect of enhancing the richness of the resultant study data and associated study findings and conclusions.

Of particular significance, given the inductive nature of this qualitative study, the process of data collection utilized open-ended questionnaires for the students and focus group discussions for the teachers. For the focus group, the data collection was executed via an online platform, whereby different participating teachers were added in a newly created group and required to participate in online discussion sessions with their colleagues at pre-set timelines by airing their views and suggestions on the study topic. As Tates et al. (2009) state, online focus groups are efficient in data collection since they are time and resource-saving compared to other methods of data collection.

\section{Data Analysis}

Data analysis for this study was executed using the thematic analysis method, which provides an invaluable mechanism for enabling an in-depth description of the qualitative dataset (Tates et al., 2009). Emerging themes from the data were categorized based on the key aims and objectives of the study, which was to investigate the impact, cause and risk factors, and viable solutions to issues of ineffective communication between students and teachers. For better evaluation and examination of the data collected, the criterion used here involved in 
summarizing the results from the survey and focus groups with subsequent analysis and discussion of findings relative to the current study aims and objectives and existing literature on the topic.

\section{Findings and Discussion}

Based on an analysis of the study data, the findings were as follows based on the key themes of the study as defined by the underlying research questions:

1) What forms of communication strategies are currently in common use between the faculty and EFL students in the EFL programs at the Mustaqbal University and Jubail University college?

2) What are the effects of current formal communication approaches on the acquisition of linguistic skills by EFL students?

3) What are the main causes of ineffective formal communication between teachers and students and how to overcome such barriers?

\subsection{Performance and Engagement between Students and Teachers}

Overall, while $39 \%$ of the respondents agreed that poor and ineffective communication is common between teachers and students in EFL programs, $44 \%$ of the respondents agreed that ineffective communication between teachers and students was a cause for the poor performance of students in EFL programs. Of particular significance, it was clear from $17 \%$ of the respondents that ineffective communication between teachers and students was to blame for the poor quality of engagement of students with their teachers as shown in figure 1.

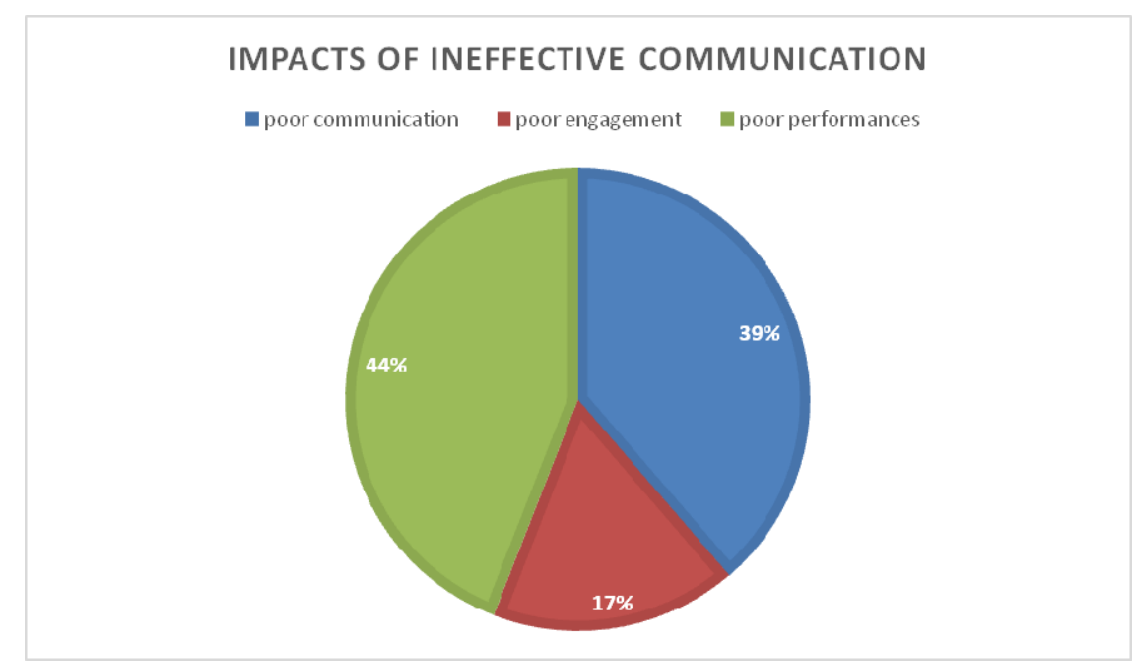

Figure 1. Impact of ineffective communication between teachers and students on the teaching and learning of EFL The findings on the impact of ineffective communication on the process and outcome of teaching and learning of EFL are supported by the finding by Aparajeya (2016) which finds a lack of effective communication between students and teachers as a leading cause for a poor learning environment and poor grades among EFL students. The findings portray a predominant view that one of the greatest impacts of poor communication is poor outcomes on academic performance and engagement. The reason behind this is that; for students to understand and have an interest in studies, they need a learning environment where there is the ease of communication between them and the teacher (Lunenburg, 2010).

As stated by one of the respondents, "ineffective communication brings about lacking understanding which decreases my interest in the class." This creates a dull environment where there is least if any, engagement interests between the teachers and students affecting the academics of students overall. As stated by one of the respondents, "lack of correct vocabulary and poor use of the right tenses affects communication." This supports the literature review which outlines that in most cases, the underlying aspects of communication, such as poor language and vocabulary use, are the most crucial factors that should be considered for effective communication (Tutkun, 2015).

\subsection{Forms of Communication and Effectiveness of Teacher-Student Communication}

A key theme that was conveyed from the findings was that the form of communication used by a teacher in engaging or communicating with the student plays a crucial role in disseminating quality information to the 
students. In the findings as presented in this study, at least $25 \%$ of the participants identified that the form or else channel of communication used in disseminating information has a quality impact. As supported by Wees (2011) and Tutkun (2015), the form of communication used dramatically affects how the information will be perceived. Most teachers employ the use of both verbal and non-verbal communication which provides a platform for students to breakdown and understand the information being conveyed (Alrabai, 2017a; Alrabai, 2018). For Khan et al. (2017), the form of communication a teacher uses to disseminate information to the students counts a lot.

As one participant stated, "As a teacher, I focus on the use of both verbal and non-verbal forms of communication; sometimes, I utilize blackboards and JUC emails for announcements and online practices." Teachers, therefore, should focus on implementing non-verbal forms of communication, on reaching out to students who may have issues with verbal communication (Albaiz, 2016; Kassem, 2019; Alrabai, 2017b). Thus, the implementation of non-verbal communication such as gestures maintains eye contact; facial expressions would be effective in improving the communication process.

\subsection{Motivating Methodologies for Improving Teacher-Student Communication}

The study findings indicated that $48 \%$ of the respondents implemented the use of small groups, while $35 \%$ preferred the use of one-on-one setups as better methods of student learning. Details of the prevalence rates among teachers in implementing various teaching methodologies for improving effective communication with students are shown in figure 2 .

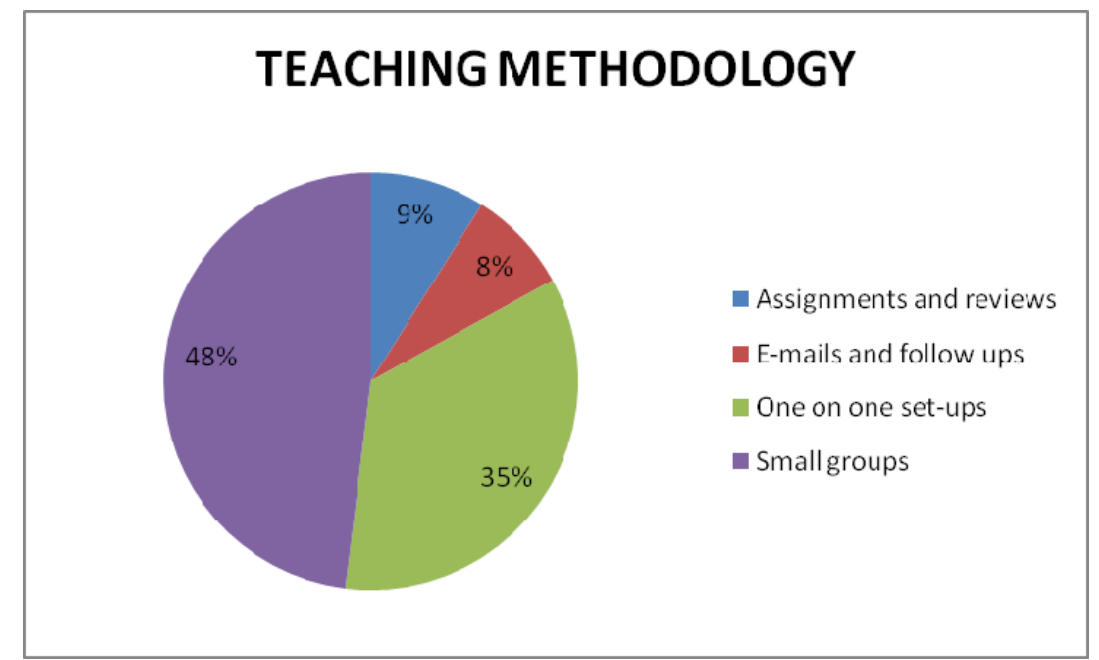

Figure 2. Prevalence rates of different teaching methodologies for improving effective communication with students among teachers

As noted by one respondent, "one on one set up has so far provided great feedback with students who have communication difficulties." Most of the instructors, in this case, believed that through such small groups and on-on-one setups, they could easily identify the students who have a problem with communication, and thus implement ways that they can interact with them better while at the same time grasp what they are being taught. The use of small groups has been proven effective as stated by one of the respondents, "Activities such as paired work or small group discussions are effective and motivating." This implies the significance of identifying student-centered teaching methodologies for promoting effective communication was recognized as a major approach for improved teaching and learning.

This statement is supported by the literature that teachers should always aim at finding the best approaches to reach out to students, to help them improve their learning (Al-Zahrani \& Rajab, 2017; Richmond, 1990). Students, who were also part of respondents, suggested that after class activities would be of great help in assisting them in improving their communication while at the same time digesting information on what they have been taught in class. An excerpt from one of the respondents stated that "Asking students at the end of every class to do exercises in class via the use of the blackboard or even books would be helpful."

\section{Conclusion}

Overall, the study findings highlight the critical role of effective communication between students and teachers as one of the determinants of the prospect of EFL programs in delivering to their expected outcomes. Specifically, the lack of effective communication within the classroom can only contribute to undue compromising of the learning 
process by fostering poor teacher-student engagement. As a result, ineffective communication exposes EFL students to unwarranted struggles in the process of acquiring a second language.

\section{Recommendations}

In the light of findings of the current study, following recommendations for improving effective formal communication between the faculty and students at Mustaqbal University and Jubail University college have been identified:

1) The background knowledge of students in relevant subjects needs to be improved to a great extent. Mostly, the students lack basic knowledge in the relevant field. As a result, they struggle to comprehend the subject matter in class.

2) The general attitude of students towards their studies should be improved. There are indications that students are not adequately motivated to enhance their performance in language learning within the institutions in question. This should be a point of reference for the administrative functions looking to ensure that the learning outcomes of the students are continuously enhanced, particularly by looking into the learning needs of the students and the paradigms that could actively influence them to adopt higher levels of motivation in learning.

3) The curriculum needs to be revised in some cases. Sometimes, the material offered to the students is either too difficult or unmotivating, in terms of the modes of delivery and the capabilities to evoke interest in learning. Consequently, students struggle to comprehend what they are supposed to learn.

4) Teachers' training for effective communication plays a vital role in effective communication between teachers and students. Unfortunately, findings reveal that this issue is yet to be addressed accordingly. For successful and effective communication, teachers should be trained properly bearing in mind the requirements of the modern era.

5) Lack of humor is one of the reasons for ineffective communication between teachers and students. Both, teacher and the students need to develop a congenial atmosphere in the class for improved and effective communication.

6) Teaching methods are sometimes, given less importance, whereas, they play a very important role to have a successful communication process in the class. For the sake of effective communication, teaching methods should be carefully selected, designed and implemented.

\section{Acknowledgement}

We gratefully thank the participants at Jubail University College and Mustaqbal University for their sincere devotion and contribution to our study.

\section{References}

Al-Ahaydib, M. E. (2005). Teaching English as a foreign language in the intermediate and secondary schools of Saudi Arabia: A diagnostic study. (Unpublished doctoral dissertation), University of Kansas

Tahany Abdulaziz Albaiz (2016). Enhancement of Higher Education Teaching of English in Saudi Arabia. US-China Education Review A, 6(6). http://dx.doi.org/10.17265/2161-623x/2016.06.001

Alhmadi, Nesreen Saud (2014). English speaking learning barriers in Saudi Arabia: A case study of Tibah University. Arab World English Journal, 5(2), 38-53.

Ali, S. S. \& Rehman, J. (2013). Indigenous peoples and ethnic minorities of Pakistan: constitutional and legal perspectives. Routledge.

Alnujaidi, S. (2018). The Relationship Between EFL Students' Perceptual Learning Styles and Their Language Learning Strategies in Saudi Arabia. International Journal of English Linguistics, 9(1), 69. http://dx.doi.org/10.5539/ijel.v9n1p69

Alrabai, F. (2016). Factors underlying low achievement of Saudi EFL learners. International Journal of English Linguistics, 6(3), 21-37. http://dx.doi.org/10.5539/ijel.v6n3p21

Alrabai, F. (2017). From teacher dependency to learner independence: a study of Saudi learners' readiness for autonomous learning of English as a Foreign Language. Learning and Teaching in Higher Education: Gulf Perspectives, 14(1), 1-28. http://dx.doi.org/10.18538/lthe.v14.n1.262

Alrabai, F. (2018). Learning English in Saudi Arabia. In English as a Foreign Language in Saudi Arabia (pp. 102-119). Routledge. 
Alrabai, F. (2017). Self-esteem of Saudi learners and its relationship to their achievement in English as a foreign language. English Linguistics Research, 6(4), 1-12. http://dx.doi.org/10.5430/elr.v6n4p1

Alrashidi, O. \& Phan, H. (2015). Education Context and English Teaching and Learning in the Kingdom of Saudi Arabia: An Overview. English Language Teaching, 8(5), 33-44. http://dx.doi.org/10.5539/elt.v8n5p33

Al-Sobhi, B. M. S. \& Preece, A. S. (2018). Teaching English speaking skills to the Arab students in the Saudi school in Kuala Lumpur: Problems and solutions. International Journal of Education and Literacy Studies, 6(1), 1-11. http://dx.doi.org/10.7575/aiac.ijels.v.6n.1p.1

Al-Zahrani, N. O. A. \& Rajab, H. (2017). Attitudes and Perceptions of Saudi EFL Teachers in Implementing Kingdom of Saudi Arabia"e s Vision 2030. world, 5(1). http://dx.doi.org/10.5296/ijele.v5i1.10733

Aparajeya. N, (2016). Lack of communication between teachers and students. Retrieved from https:/www.toppr.com/bytes/failure-communication-between-teachers-and-students/

Burns, A. \& Seidlhofer, B. (2010). Speaking and pronunciation. An introduction to applied linguistics, 197-214. https://doi.org/10.1093/applin/amt046

Chalhoub-Deville, M. \& Deville, C. (2008). Utilizing psychometric methods in assessment. Encyclopedia of language and education, 7, 211-224.

Criper, C. \& Widdowson, H. G. (1975). Sociolinguistics and language teaching. Papers in Applied Linguistics: Edinburgh Course in Applied Linguistics, 2, 155-217.

Dewaele, J. M. \& Alfawzan, M. (2018). Does the effect of enjoyment outweigh that of anxiety in foreign language performance? Studies in Second Language Learning and Teaching, 8(1). http://dx.doi.org/10.14746/ssllt.2018.8.1.2

Fageeh, A. A. I. (2013). Effects of MALL applications on vocabulary acquisition and motivation. Arab World English Journal, 4(4). ISSN: 2229-9327.

Kassem, H. M. (2019). The Impact of Student-Centered Instruction on EFL Learners' Affect and Achievement. English language teaching, 12(1), 134-153. http://dx.doi.org/10.5539/elt.v12n1p134

Khan, A., Khan, S., Zia-Ul-Islam, S. \& Khan, M. (2017). Communication Skills of a Teacher and Its Role in the Development of the Students' Academic Success. Journal of Education and Practice, 8(1), 18-21. ISSN 2222-1735

Khan, I. A. (2011). Learning difficulties in English: Diagnosis and pedagogy in Saudi Arabia. Educational Research, 2(7), 1248-1257. ISSN: 2141-5161

Khan, R. M. I., Radzuan, N. R. M., Shahbaz, M. \& Ibrahim, A. H. (2018). EFL Instructors' Perceptions on the Integration and Implementation of MALL in EFL Classes. International Journal of Language Education and Applied Linguistics, 39-50. ISSN: 2289-7208

Khan, R. M. I., Radzuan, N. R. M., Alkhunaizan, A. S., Mustafa, G. \& Khan, I. (2019). The Efficacy of MALL Instruction in Business English Learning. International Journal of Interactive Mobile Technologies (iJIM), 13(08), 60-73. eISSN: 1865-7923

Khan, R. M. I., Radzuan, N. R. M., Shahbaz, M., Ibrahim, A. H. \& Mustafa, G. (2018). The role of vocabulary knowledge in speaking development of Saudi EFL learners. Arab World English Journal (AWEJ) Volume, 9. https://dx.doi.org/10.2139/ssrn.3151128

Kiraly, D. (2014). A social constructivist approach to translator education: Empowerment from theory to practice. Routledge.

Lotich, Patricia. (2011). What is the purpose and advantages of focus group interviews? SocialMediaToday, 16 $\begin{array}{lllll}\text { August } & 2011 . & \text { Web. } & 17 & \text { December }\end{array}$ $<\mathrm{https}$ ://www.socialmediatoday.com/content/what-purpose-and-advantages-focus-group-interviews $>$

Lunenburg, F. C. (2010). Communication: The process, barriers, and improving effectiveness. Schooling, 1(1), $1-10$.

Mutambik, Ibrahim Mohammed Othman. (2018). Exploring the readiness of students and English teachers to use e-learning for English as a foreign language in Saudi Arabia. (Unpublished doctoral dissertation), University of Edinburgh.

Neill, S. (2017). Classroom nonverbal communication. Routledge. 
Rahman, M. S. (2017). The Advantages and Disadvantages of Using Qualitative and Quantitative Approaches and Methods in Language Testing and Assessment Research: A Literature Review. Journal of Education and Learning, 6(1), 102-112. http://dx.doi.org/10.5539/jel.v6n1p102

Reading Craze. (2019). Open-ended questions advantages and disadvantages. Reading Craze, 20 April 2017. Web. 18 December 2019. <http://readingcraze.com/index.php/open-ended-questions-advantages-disadvantages/>

Richmond, V. P. (1990). Communication in the classroom: Power and motivation. Communication Education, 39(3), 181-195. https://doi.org/10.1080/03634529009378801

Saunders, S. \& Mills, M. (1999). The knowledge of communication skills of secondary graduate student teachers and their understanding of the relationship between communication skills and teaching. Retrieved Feb, 4, 2010.

Shahbaz, M. \& Khan, R. M. I. (2017). Use of mobile immersion in foreign language teaching to enhance target language vocabulary learning. MIER Journal of Educational Studies, Trends and Practices, 7(1).

Shahbaz, M., Khan, M. S., Khan, R. M. I. \& Mustafa, G. (2016). Role of self-perceived communication competence and communication apprehension for willingness to communicate in L1 and L2. Journal of Educational and Social Research, 6(1), 158. http://dx.doi.org/10.5901/jesr.2016.v6n1p158

Tates, K., Zwaanswijk, M., Otten, R., van Dulmen, S., Hoogerbrugge, P. M., Kamps, W. A. \& Bensing, J. M. (2009). Online focus groups as a tool to collect data in hard-to-include populations: examples from paediatric oncology. BMC Medical Research Methodology, 9(1), 15. http://dx.doi.org/10.1186/1471-2288-9-15

Tutkun, O. F. (2015). Prospective teacher's communication skills level: intellectual, emotional and behavioral competencies. The Anthropologist, 19(3), 665-672.

Velentzas, J. O. H. N. \& Broni, G. (2014). Communication cycle: Definition, process, models and examples. Recent advances in financial planning and product development, 117-131.

Wees, David. (2011). The effect of communication tools on education. The Reflective Educator, 25 April 2011. Web. 19 December 2019. https://davidwees.com/content/effect-communication-tools-education/

\section{Copyrights}

Copyright for this article is retained by the author with first publication rights granted to the journal.

This is an open-access article distributed under the terms and conditions of the Creative Commons Attribution license (http://creativecommons.org/licenses/by/3.0/). 